\title{
Determination of dihydrocapsaicin adulteration in dietary supplements using LC-MS/MS
}

\author{
Demet Dincel ${ }^{1 *}$, Hatice Olgan ${ }^{1}$, Zeynep Canbaloğlu ${ }^{1}$, \\ Sule Yalcin $\oplus^{2}$, Ayşen Erkuçuk $\oplus^{3}$, Gizem Tırıs $\oplus^{1}$ and Ahmet C. Gören $\oplus_{1,2}$ \\ ${ }^{1}$ Department of Analytical Chemistry, Faculty of Pharmacy, Bezmialem Vakif University, 34093, Istanbul, \\ Türkiye \\ ${ }^{2}$ Drug Application and Research Center (ILMER), Bezmialem Vakif University, 34093, \\ Istanbul, Türkiye \\ ${ }^{3}$ Department of Pharmacognosy, Faculty of Pharmacy, Bezmialem Vakif University, 34093, \\ Istanbul, Türkiye
}

(Received January 21, 2020; Revised April 15, 2020; Accepted April 16, 2020 )

\begin{abstract}
Adulteration of dietary supplements are serious threats to public health in all around of world. Nowadays, in order to obtain the intended effect from natural remedies, the adulteration of natural products via artificial or harmful chemicals are increasing. A rapid LC-MS/MS method for determination of capsaicin and dihydrocapsaicin in dietary supplements via Fortis $\mathrm{C} 18(150 \times 3 \mathrm{~mm} ; 3 \mu \mathrm{m})$ column at $25{ }^{\circ} \mathrm{C}$ was developed and validated in a mixture of mobile phase A ( $1 \%$ formic acid solution and $0.1 \%$ ammonium formate in water) and B (1\% formic acid solution and $0.1 \%$ ammonium formate in methanol) with gradient program at a flow rate of $0.35 \mathrm{~mL} / \mathrm{min}$. The recoveries of developed methods weytre obtained in the range of \% 95.4-106.3 for capsaicin and \% 96.3-108.9 for dihydrocapsaicin. This study shows that synthetic compound dihydrocapsaicin is widely use in dietary supplements products for adulteration to increase the effects of product without any declaration.
\end{abstract}

Keywords: Capsaicin; dihydrocapsaicin; LC-MS/MS; adulteration; dietary supplements; lose weight. ㄷ 2020 ACG Publications. All rights reserved.

\section{Sample Source}

Ten (10) different kinds of dietary supplement products were purchased from the local pharmacies and herbalists in Istanbul. The commercial products are numbered as A-J to avoid from law enforcement of the authors. Detailed ingredients of studied samples are given in Table S1 in supporting information.

\section{Previous Studies}

Capsaicinoids are irritants derived from peppers [1]. Capsaicin and dihydrocapsaicin (Figure S1) are the most potent of capsaicinoids in chili pepper and composed about $90 \%$ [2]. Capsaicin is derived from "Capsicum annum" pepper [3] and it was firstly isolated by PA Buchtholz in 1816 and named "capsaicin" by LT Tresh in 1846. Capsicum species called as "chili peppers" are very popular as food

\footnotetext{
*Corresponding author: ddincel@bezmialem.edu.tr
} 
additives [4] and those are the sources of chili pepper sensory attributes of color, bitterness and aroma. Besides, chili pepper pills, which are generally in capsule form, are widely used for losing weight. Since the reported effects of chili pepper (e.g. Mexican pepper, Thai peppers, etc.) on the for losing weight via fat oxidation, the great attention observed to that herbal products and its main and active components of capsaicin [5]. Current studies demonstrated strong indication for significant and positive effects of chili consumption in aggravating energy metabolism. Scientists found that in recent studies where patients had a mean BMI (Body Mass Index) falling within the overweight or obese range, ingestion of capsaicin or capsinoids increased energy expenditure and fat oxidation [6].<smiles>COc1cc(CNC(=O)CCCC/C=C/C(C)C)ccc1O</smiles>

a<smiles>COc1cc(CNC(=O)CCCCCCC(C)C)ccc1O</smiles>

b

Figure 1. The chemical structure of a: capsaicin b: dihydrocapsaicin

In addition to the positive effects of capsaicin, negative effects were also observed in case of excessive consumption or according to the sensitivity of the consuming person. It has an irritating effect on the digestive system [2] especially starting in the mouth, for example it can irritate the mucous membranes in the mouth. Also, it is very irritating to the skin and eyes [7], and it causes swelling in pulmonary tissue $[8,9]$

Several methods were reported for the determination of capsaicinoids in herbal products and pepper by SPME-MS (Solid phase microextraction-mass spectrometry), HPLC (High performance liquid chromatography) and LC-MS/MS (Liquid chromatography coupled with tandem mass spectrometry) [3, 10]. The liquid chromatography (LC)-mass spectrometry (MS) methods [11] have many advantages over the traditional analytical techniques, such as short analysis time, high specificity and sensitivity. In addition to this, capsaicin has been determined in biological fluids by several HPLC and LC-MS/MS techniques, for example in animal tissues (rat brain, spinal cord and the liver) and blood samples by HPLC techniques [12].

\section{Present Study}

Obesity is a chronic disease characterized by the increase in body fat mass compared to lean body mass, due to the fact that the energy taken from the food through the body is higher than the energy consumed [13]. WHO's (The World Health Organization) definition of obesity is the accumulation of abnormal or excessive fat in the body to the extent that health is impaired [14]. Obesity is a health problem found in all developed and developing countries. It affects all organs and systems, of the body, especially the endocrine and cardiovascular system. The most effective way to treat obesity is diet and sports. However, some patients resort to certain chemical or vegetable products to obtain results in a shorter time without getting help from professionals and changing their diet. Herbal dietary supplements are released to the market with the promise of effective weight loss [15]. Some of these products cause serious side effects even if they lose weight. Unfortunately, there is an idea that natural or herbal products are harmless in the society. Using this idea, many plant-sourced products are produced and sold on the market as food supplements to help weaken today.

Many of the dietary supplements on the market are licensed by the Ministry of Food and Agriculture in Turkey. Even the control process in any licensing procedure, the further batch and products needs to be regularly checked.

The aim of this study is to show the extraction efficiency of the several techniques (water bath, ultrasonic bath and soxhlet extractions) and validation of LC-MS/MS method for determination of capsaicin and dihydrocapsaicin in dietary supplements. Herein, the survey about the capsaicin and 
dihydrocapsaicin in diatery supplements from Turkish market in Istanbul are reported. The used chemicals and experimental procedure are described below.

Chemicals and Reagent: Capsaicin (95\%, Sigma-Aldrich) and dihydrocapsaicin (85\%, Sigma Aldrich), Curcumin (97\% in house qNMR (quantitative Nuclear Magnetic Resonance) purity, internal standard, IS) were used. Ethanol and methanol (HPLC grade), analytical grade formic acid were purchased from Merck (Darmstadt, Germany). Ultrapure water was obtained from Human Power water system (Tetra Technology Systems).

Preparation of Stock and Working Solutions and Extractions: The stock solution of capsaicin and dihydrocapsaicin $(10 \mathrm{mg} / \mathrm{L})$ was daily prepared in methanol. The calibration standards were diluted from the stock solutions of capsaicin and dihydrocapsaicin at final concentrations of $0.05,0.1,0.3,1$ and 2 $\mu \mathrm{g} / \mathrm{mL}$ (Figure 2). Stock solution of IS was prepared at $500 \mathrm{mg} / \mathrm{L}$ concentration of curcumin in methanol. Standard solution was daily prepared by diluted the stock solution at final concentration of $3 \mathrm{mg} / \mathrm{L}$ (Figure 2). In order to optimize the extraction methods we tried three different extraction methods of dietary supplements i.e. Soxhlet extraction, ultrasonic extraction, and water bath reflux extraction. The detail of extraction procedures are given in the supporting information.

LC-MS/MS Measurements: The LC-MS/MS method was adopted to use to disappear the negative effects of interferences due to required selectivity and precision in this matrix. In this study, numerous compounds were tested for internal standard and decided to use curcumin and no interference observed with the matrix. Similar to previous reports of literature, a good ionization was observed with formic acid in water and methanol mobile phase system by ESI source [16-18].

Equipment and Chromatographic Conditions: LC-MS/MS experiments were performed on a Zivak Technologies, Zivak Multitasker and Zivak Tandem Gold Triple quadrupole system (Istanbul, Turkey). The samples were separated on a C18 $(150 \times 3 \mathrm{~mm} ; 3 \mu \mathrm{m})$ column (Fortis Technologies, UK) at $25{ }^{\circ} \mathrm{C}$. The mobile phase was a mixture of mobile phase A $(1 \%$ formic acid solution and $0.1 \%$ ammonium formate in water) and B (1\% formic acid solution and $0.1 \%$ ammonium formate in methanol), the gradient program of which was $0-1.00 \mathrm{~min} 50 \% \mathrm{~A}$ and $50 \% \mathrm{~B}, 1.01-3.00 \mathrm{~min} 2 \% \mathrm{~A}$ and $98 \% \mathrm{~B}, 3.01-$ $6.00 \mathrm{~min} 2 \% \mathrm{~A}$ and $98 \% \mathrm{~B}, 6.01-7.00 \mathrm{~min} 50 \% \mathrm{~A}$ and $50 \% \mathrm{~B}$ and finally $7.01-10.00 \mathrm{~min} 50 \% \mathrm{~A}$ and $50 \% \mathrm{~B}$. The flow rate of the mobile phase was $0.35 \mathrm{~mL} / \mathrm{min}$. The injection volume was $10 \mu \mathrm{L}$.

Optimization of LC-MS/MS Procedure: The chromatographic conditions, particularly the composition of mobile phase and its $\mathrm{pH}$, were optimized through several trials to achieve good sensitivity and symmetric peak shapes of analytes. For that purpose, at various flow rates different solvents of mixtures, such as methanol, acetonitrile, formic acid, and acetic acid were tested. The best results were acquired using methanol: formic acid as the mobile phase and was applied gradient programme. The mobile phase was found to be substantial for the ionization abundance and separation of the compounds. The appropiate ionization of capsaicinoids was gained by the ESI (electrospray ionization) source. The optimum ESI parameters were determined as $2.40 \mathrm{mT}$ Torr CID gas pressure, $5000.00 \mathrm{~V}$ ESI needle voltage, $600.00 \mathrm{~V}$ ESI shield voltage, $300.00{ }^{\circ} \mathrm{C}$ drying gas temperature, $50.00{ }^{\circ} \mathrm{C}$ API housing temperature, 55 psi nebulizer gas pressure, and 40.00 psi drying gas pressure.

Parent ions and daughter ions of each compound were identified together with retention times of them on Fortis C18 column $(150 \times 3 \mathrm{~mm} ; 3 \mu \mathrm{m})$ column using mobile phase A and mobile phase B. Identification of the analytes done by those MS/MS patterns of each compound and their retention times in C18 column (Figure S1 and Figure S2).

Method Validation Applied Method: The method validated based on the following criteria: linearity, repeatability, recovery, limit of detection (LOD), and limit of quantification (LOQ). In order to calculate LOD and LOQ values, the mass fraction of the sample was divided by signal to noise $(\mathrm{S} / \mathrm{N})$ ratio and then obtained value was multiplied by 3 and 10 to obtain LOD and LOQ, respectively [17, 19]. The correlation coefficients $\left(\mathrm{R}^{2}\right)$ and linear regression equations of were determined as $\mathrm{y}=0.1066 \mathrm{x}-0.0031$ for 
capsaicin and $\mathrm{y}=3.6824 \mathrm{x}-0.1965$ for dihydrocapsaicin, where $\mathrm{y}$ is the peak area and $\mathrm{x}$ is the concentration. The linearity for each compound for the reported method was determined by analyzing standard solutions. The summary of validation data used ions and uncertainty data for each compound are given in Table 1.

Table 1. Validation and uncertainty parameters of LC-MS/MS method*

\begin{tabular}{lccccccc} 
& $\begin{array}{c}\text { Parent } \\
\text { ion }\end{array}$ & $\begin{array}{c}\text { Daughter } \\
\text { ion }\end{array}$ & $\begin{array}{c}\text { Collision } \\
\text { energy } \\
(\mathbf{V})\end{array}$ & $\mathbf{R}^{2}$ & $\begin{array}{c}\mathbf{L O D} \\
(\boldsymbol{\mu} \mathbf{g} / \mathbf{m L})\end{array}$ & $\begin{array}{c}\mathbf{L O Q} \\
(\boldsymbol{\mu} \mathbf{g} / \mathbf{m L})\end{array}$ & $\mathbf{U}(\mathbf{k}=\mathbf{2})$ \\
\hline Capsaicin & 304.4 & 167.6 & 12 & 0.998 & 0.01 & 0.03 & 5.8 \\
Dihydrocapsaicin & 308.3 & 136.9 & 12 & 0.993 & 0.01 & 0.03 & 8.9 \\
Curcumin IS & 367.5 & 216 & 12 & & & & \\
\hline
\end{tabular}

Uncertainty Evaluation of Applied Method: Sources and quantification of the uncertainty for the developed method were determined by using EURACHEM/CITAC guide [17, 18, 20]. The sources of uncertainties are determined as purity of standards, peperation of stock solutions (including weighings), calibration curve and recoveries. For both analytes, the maximum contribution comes from the purity of standards and recovery of method. The percent relative uncertainties of capsaicin and dihydrocapsaicin were determined $5.8 \%$ and $8.9 \%$, respectively, at 95\% confidence level $(k=2)$. The biggest contributions to uncertainty budget comes from purity of standards (49\% and $67 \%)$ and recoveries of experiments $(4.5 \%$ and $29.1 \%)$, respectively.

Evalaution of Extraction Efficiencies: Water bath reflux extraction, ultrasonic bath extraction and Soxhlet extractions were evaluated in order to decide rapid, repeatable and accurate sample preparation to analyze capsaicin and dihydrocapsaicin in dietary supplements. Detail of extraction methods are given in supporting information. 30 capsules of each product were weighed as 3 replicates. The contents of capsules were powdered in a mortar and filled to cellulose cartridges and extracted with $250 \mathrm{~mL}$ of ethanol for 2 hours in a Soxhlet apparatus. After two hours the reflux is stopped and solvent were evaporated via rotary evaporator and the remaining extract was weighed. After all extractions, $5 \mathrm{~mL}$ of ultra-pure water and $15 \mathrm{~mL}$ of methanol were added to the remaining extracts in the flask. It was allowed to dissolve in the ultrasonic bath for 5 minutes. If completely dissolved, the flask was transferred to a 100 $\mathrm{mL}$ flask and made up to $100 \mathrm{~mL}$ with methanol. After mixing with vortex, it was filtered through a 0.40 $\mu$ filter and placed into vials. Then, it was injected to the LC-MS/MS system. From those methods, we eliminated the ultrasonic bath extraction due to lower recovery $(<80 \%)$ performance of it. Then we concentrated to water bath reflux and Soxhlet extraction techniques for the further measurements.

Table 2. Recovery Performances of Water bath reflux extraction and soxhlet extraction techniques.

\begin{tabular}{ccc}
\hline $\begin{array}{c}\text { Code of Spiked } \\
\text { Product }\end{array}$ & $\begin{array}{c}\text { Recovery \% } \\
\text { (capsaicin) }\end{array}$ & $\begin{array}{c}\text { Recovery \% } \\
\text { (dihydrocapsaicin) }\end{array}$ \\
\hline $\mathrm{F}^{\mathrm{a}}$ & 95.4 & 97.6 \\
$\mathrm{~F}^{\mathrm{b}}$ & 98.7 & 99.7 \\
$\mathrm{~J}^{\mathrm{a}}$ & 106.3 & 98.9 \\
$\mathrm{~J}^{\mathrm{b}}$ & 97.9 & 108.9 \\
$\mathrm{H}^{\mathrm{a}}$ & 102.7 & 106.6 \\
$\mathrm{H}^{\mathrm{b}}$ & 97.9 & 96.3 \\
\hline
\end{tabular}

${ }^{\mathrm{a}}$ Water bath reflux; b ${ }^{\text {Soxhlet extraction }}$ 
The recovery performances of later techniques are given in Table 2. According to those data we confirmed that water bath reflux extraction and Soxhlet extraction techniques can be used for determination of capsaicin and dihydrocapsaicin in dietary supplements (find the detail of methods in supporting information) in routine measurements. However we decided to use Soxhlet extraction technique regarding to less solvent consumption successive extractions. This also reduce to evaporation process as well.

Based on above data, we used soxhlet extraction method for the sample preperation for determination of capsaicin and dihydrocapsaicin in herbal products. The results of market survey are given in Table 3.

Table 3. Concentration of capsaicin and dihydrocapsaicin in some dietary supplements in Turkish Market via soxhlet extraction-LC-MS/MS*

\begin{tabular}{|c|c|c|}
\hline Product Code & Capsaicin & Dihydrocapsaicin \\
\hline $\mathbf{A}$ & $<$ LOD & 0.11 \\
\hline B & $<$ LOD & 0.05 \\
\hline C & $<$ LOD & 0.07 \\
\hline D & $<$ LOD & 0.05 \\
\hline $\mathbf{E}$ & $<$ LOD & 0.05 \\
\hline $\mathbf{F}$ & $<$ LOD & $<\mathrm{LOD}$ \\
\hline G & $<$ LOD & $<\mathrm{LOD}$ \\
\hline $\mathbf{H}$ & $<\mathrm{LOD}$ & $<\mathrm{LOD}$ \\
\hline I & $<\mathrm{LOD}$ & 0.05 \\
\hline $\mathbf{J}$ & $<\mathrm{LOD}$ & $<\mathrm{LOD}$ \\
\hline
\end{tabular}

*Uncertainty of data are not given. Please see Table 1 for relative uncertaintiy budget.

As a conclusion, according to our survey 6 herbal product found as adulterated among 10 sample which are obtained from herbalist and pharmacies in Istanbul. This study clearly shows that synthetic compound dihydrocapsaicin is widely use in dietary supplements products for adulteration to increase the effects of product without any declaration.

\section{Acknowledgments}

This article is a part of the graduation thesis of Hatice Olgan. We gratefully acknowledge financial support from the Bezmialem Vakif University, Faculty of Pharmacy .

\section{Supporting Information}

Supporting information accompanies this paper on http://www.acgpubs.org/journal/journal-ofchemical-metrology

\section{ORCID}

Demet Dincel: 0000-0001-8319-9307

Hatice Olgan: 0000-0002-8070-706X

Zeynep Canbaloglu: 0000-0001-6549-9349

Sule Yalcin: 0000-0003-4974-2905

Aysen Erkucuk: 0000-0002-2415-099X

Gizem Tiris: 0000-0002-2547-6086

Ahmet C. Gören: 0000-0002-5470-130X

\section{References}

[1] Y. Shim, J. Kim, and S. Jeong (2016). Simultaneous determination of piperine, capsaicin, and dihydrocapsaicin in Korean instant-noodle (Ramyun) soup base using high-performance liquid chromatography with ultraviolet detection, J. AOAC Int. 99(1), 187-92. 
[2] Z. Othman, Y. Ahmed, M. Habila and A. Ghafar (2011). Determination of capsaicin and dihydrocapsaicin in Capsicum fruit samples using high performance liquid chromatography, Molecules 16 (10), 8919-8929.

[3] A. Durak, I. Kowalska and U. Gawlik-Dziki (2016). UPLC-MS method for determination of phenolic compounds in chili as a coffee supplement and their impact of phytochemicals interactions on antioxidant activity in vitro, Acta Chromatogr. 30 (1), 66-71.

[4] A. Alvarez, E. Maya and L. Suarez (2009). Analysis of capsaicin and dihydrocapsaicin in peppers and pepper sauces by solid phase microextraction-gas chromatography-mass spectrometry, J. Chromatogr. A, 1216 (14), 2843-2847.

[5] S. Varghese, P. Kubatka, L. Rodrigo, K. Gazdikova, M. Caprnda, J. Fedotova, A. Zulli, P. Kruzliak and D. Büsselberg (2017). Chili pepper as a body weight-loss food, Int. J. Food Sci. Nutr. 68 (4), 392-401.

[6] J. Zheng, S. Zheng, Q. Feng, Q. Zhang and X. Xiao (2017). Dietary capsaicin and its anti-obesity potency: from mechanism to clinical implications, Biosci. Rep, 37 (3), 1-9.

[7] S. Williams, R. Clark and J. Dunford (1995). Contact dermatitis associated with capsaicin: hunan hand syndrome, Ann Emerg. Med. 25 (5), 713-715.

[8] J. Burnett (1989). Capsicum pepper dermatitis. Cutis, 43 (6), 534-534.

[9] C. Reilly, J. Taylor, D. Lanza, B. Carr, D. Crouch and G. Yost (2003). Capsaicinoids Cause inflammation and epithelial cell death through activation of vanilloid receptors, Toxicol. Sci. 73 (1), 170-181.

[10] N. Kozukue, J. Han, E. Kozukue, S. Lee, J. Kim, K. Lee, C. Levin and M. Friedman (2005). Analysis of eight capsaicinoids in peppers and pepper-containing foods by high-performance liquid chromatography and liquid chromatography-mass spectrometry, J. Agric. Food Chem. 53 (23), 9172-9181.

[11] J. Rosas, J. Martinez, P. Alonso, R. Miranda, L. Velasco, L. Rubio-Perez and J. Perez (2019). Alternative mass spectrometry techniques for the validation of the fragmentation pattern of capsaicin and dihydrocapsaicin, Rapid Commun. Mass Spectrom. 33 (7), 635-640.

[12] A. Saria, F. Lembeck and G. Skofitsch (1981). Determination of capsaicin in tissues and separation of capsaicin analogues by high-performance liquid chromatography, J. Chromatogr. A, 208 (1), 41-46.

[13] M. Yıldırım, A. Aksoy and G. Ersoy (2008). Şişmanlık (obezite) ve fiziksel aktivite enerji dengesinin aktivite yönüne bir bakış, Klasmat Matbaacılık.

[14] S. Otake, H. Takeda, Y. Suzuki, T. Fukui, S. Watanabe and K. Ishihama (2005). Association of visceral fat accumulation and plasma adiponectin with colorectal adenoma: evidence for participation of insulin resistance, Clin. Cancer Res. 11 (10), 3642-3646.

[15] K. Karaalp (2014). Bitkisel zayıflama ürünleri. Arch. Clin. Toxicol. 1 (1), 13-17.

[16] S. Çarıkçı, S. Kılıç, T. Özer, Z. Dirmenci, T. Arabaci and A. C. Gören (2018). Quantitative determination of some phenolics in origanum laevigatum boiss. extracts via validated LC-MS/MS method and antioxidant activity, J. Chem. Metrol. 12, 121-127.

[17] S. Oguzkan, B. Karagul, E. Aksoy, A. Uzun, M. Can, H. Yilmaz, H. Ugras, B. Binici and A.C. Goren (2018). Determination of taxanes by validated lc-ms/ms method in hazelnut collected from different regions and altitudes in Turkey, J. Chem. Metrol. 12 (1), 26-33.

[18] H. Han, H. Yilmaz and I. Gulcin (2018). Antioxidant activity of flaxseed (linum usitatissimum 1.) shell and analysis of its polyphenol contents by LC-MS/MS, Rec. Nat. Prod. 12 (4), 397-402.

[19] A.C. Gören, G. Bilsel, M. Bilsel, S. Karakaş and D. Karakas (2005). Simple high-performance liquid chromatographic method for determination of atropine and obidoxime in a parenteral injection device, $J$. Chromatogr. A, 1057 (1), 237-239.

[20] S. L. R. Ellison and A.Williams (2012). Eurachem/CITAC Guide CG4, Quantifying Uncertainty in Analytical Measurement. Third edition.

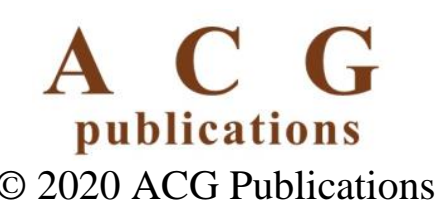

